九州大学学術情報リポジトリ

Kyushu University Institutional Repository

\title{
dSPACE based Hardware in the loop Testing Platform for Powertrain Management Unit of Electric Tractor
}

WU, Zhongbin

College of Engineering, China Agricultural University

$X I E$, Bin

College of Engineering, China Agricultural University

LI, Zhen

College of Engineering, China Agricultural University

MITSUOKA, Muneshi

Laboratory of Agricultural Machinery and Production Systems Design, Division of Bioproduction Environmental Sciences, Department of Agro-environmental Sciences, Faculty of Agriculture, Kyushu University

他

https://doi.org/10.5109/2340993

出版情報: 九州大学大学院農学研究院紀要. 64 (2)，pp. 309-317，2019-09-02. Faculty of Agriculture, Kyushu University

バージョン：

権利関係 : 


\title{
dSPACE based Hardware in the loop Testing Platform for Powertrain Management Unit of Electric Tractor
}

\author{
Zhongbin WU, ${ }^{1,2}$, Bin XIE ${ }^{1,2}$, Zhen LI ${ }^{1,2}$, Muneshi MITSUOKA ${ }^{3}$, Eiji INOUE ${ }^{3}$, \\ Takashi OKAYASU ${ }^{3}$ and Yasumaru HIRAI ${ }^{3}$
}

Laboratory of Agricultural Machinery and Production Systems Design, Division of Bioproduction Environmental Sciences, Department of Agro-environmental Sciences, Faculty of Agriculture, Kyushu University, Fukuoka 819-0395, Japan

(Received May 7, 2019 and accepted May 8, 2019)

\begin{abstract}
This study developed a hardware in the loop (HIL) test platform using dSPACE for performance testing and verification of the powertrain management unit (PMU) for an electric tractor. The HIL test platform mainly comprised the PMU and a dSPACE/DS1007 board. The PMU was specially designed to manage the tractor operating state refresh and calculate the target torque required in the driving state. The dSPACE/ DS1007 board was used for real time simulation of the dynamic behavior of the powertrain, including the electric motor and the battery, as well as the tractor itself. The mathematical models of the powertrain components supported by the dSPACE/DS1007 board were presented and the calibration of the PMU control parameters was introduced. HIL simulations of the tractor operating state refresh and driving torque calculation under full-throttle acceleration were carried out. The test results showed that the PMU was capable of correctly switching the operating state of the electric tractor according to driver inputs without repetition or omission. In the acceleration test, the PMU accurately provided the torque demand in response to the driving intentions. Further, it controlled the torque demand according to the torque increase limits, torque capacity, and battery voltage level. These controls respectively eliminated the possible shocks due to torque fluctuations, avoided overloading of the electric motor, and prevented the battery from overdischarging.
\end{abstract}

Key words: Electric tractor, hardware-in-the-loop, powertrain, control

\section{INTRODUCTION}

With the rapid growth of tractor use in the world, people are increasingly aware of the harm that traditional tractors do to the environment. The urgency of our environmental problems spurs many people to reconsider the future power supply of agricultural machinery (Mousazadeh et al., 2010; Moreda et al., 2016). Despite the availability of various new fuels, battery-powered electric tractors (ETs) are considered as one of the main choices for the development of agricultural tractors in the future (Gonzalez de Soto et al., 2016). With the technological progress of batteries and vehicle purposed electric motors over the past few decades, the ET has received more attention (Obert, 1972; Alcock, 1986; Arjharn et al., 2001). The industrial leadacid battery, which proved to be useless for heavy field tasks, has been replaced by the new lithium-ion battery, which possesses high energy density, high power density, safety, and portability (Hammond and Hazeldine, 2015; Liu et al., 2015). Meanwhile, electric motors specially designed for vehicle use have also been verified as

College of Engineering, China Agricultural University, Beijing 100083, China

${ }^{2}$ Beijing Key Laboratory of Optimized Design for Modern Agricultural Equipment, China Agricultural University, Beijing 100083, China

${ }^{3}$ Laboratory of Agricultural Machinery and Production Systems Design, Division of Bio-production Environmental Sciences, Department of Agro-environmental Sciences, Faculty of Agriculture, Kyushu University, Japan

* Corresponding author (E-mail: zhenli@cau.edu.cn) more suitable for tractor operating conditions than previous industrial motors (Stöck et al., 2015; Soda and Enokizono, 2017; Fatemi et al., 2018).

The progress of these key driveline components increases the sophistication of ET technology, which necessarily requires a corresponding upper controller to manage the lower level components, such as the battery, motor, and electric accessories. The powertrain management unit (PMU), which collects signals from the motor driving system, the battery management system, and other external devices, is the core control component of an ET (Wu et al. 2019). To coordinate the operation of the components, the PMU is required to calculate the target torque in consideration of both the driving intentions and restrictions from the tractor operating status. For this reason, the PMU typically employs a large number of control parameters that must be calibrated to adapt them to the various performance requirements of tractors. The traditional way to determine the values of the control parameters usually depends on field testing a tractor prototype, which has to go through at least three phases powertrain test bench construction, controller communication testing, and control parameters calibration (Min, 2011). With the widespread application of electronic control technology in tractors, the time, manpower, and material resources spent on controller function and performance calibration are increasing. This results in a correspondingly longer development cycle for the whole machine, a situation that is particularly prominent for electric tractors.

As an off-road vehicle, the tractor has to travel 
through various complex outdoor environments, which inevitably places higher requirements on the design and calibration of the controller. To adapt to extreme working conditions, the calibration and verification of tractor controllers on a drum test bench are often very complex and cumbersome. However, given the difficulty of precisely and comprehensively controlling the dynamic behavior of the tractor, some unexpected situations are very likely to occur during the testing process. Meanwhile, because the calibration work cannot be carried out until a prototype has been manufactured, the development cost and cycle of the controller are greatly increased. All these factors make it difficult to achieve a comprehensive and accurate calibration for the PMU for electric tractors.

By performing the test procedures in an indoor environment, virtual calibration is able to accurately evaluate the control performance and comprehensively simulate the dynamic behavior of tractors under various conditions (Nelson, 2013; Abdelrahman et al., 2018; Schreiber et al., 2018). However, this technology, as far as we know, has generally not been applied to PMU design and calibration for electric tractors. Likewise, a hardware in the loop (HIL) test platform for PMU calibration has not yet been fully developed.

In this study, we developed a PMU for a batterypowered ET to coordinate the drivetrain components and ensure that the tractor can operate safely and smoothly according to the driving intention. Meanwhile, to shorten the development cycle and decrease the development cost of the PMU, we are also seeking to design a HIL test platform using dSPACE. In this way, the verification of the control strategies of the PMU are expected to be carried out in advance using virtual mathematical ET models.

\section{MATERIALS AND METHODS}

The ET powertrain control system is a complex system composed of several controllers, including the PMU, motor controller, battery management unit (BMU), instrument control unit, and other auxiliary control units. Among them, the PMU is the main controller, which is responsible for managing the operating state of the tractor, controlling information interactions among the components of the powertrain, and interpreting of the driving requirements.

\section{ET operating state and switching logic}

After establishing the topology of the ET powertrain control network, we need to define the operating states and the logic for switching among the defined states to coordinate the parallel operation of the three controllers. Note that each state that determines how the tractor behaves at a particular moment must be unique and not intersect other states. Meanwhile, a union of all defined states is required to completely cover all the dynamic behaviors of the electric tractor. Any repetition or omission of a vehicle state may lead to no correspondence or multiple correspondences in the control program, which therefore is likely to result in dangerous ET behavior. Seven states were established in this study to describe all the possible behaviors of an ET ready state, starting state, driving state, charging state, charge during state, fault state, and return state, as shown in Fig. 1.

(1) Ready state

When the ET is in the ready state, the PMU is first required to determine whether the BMU is requesting battery charging, and if so, change the tractor state to charging, as shown in Fig. 2. Otherwise, the PMU continues monitoring the position of the key switch, which can be off, on, or start. The pre-charge contactor, which is designed to reduce or eliminate current surge when the main contactor is closed and is connected in parallel with the main contactor between the power battery and the motor controller (Fig. 3), is closed first when the key is switched on. After that, the PMU continues to wait for the start signal from the key switch and changes the tractor state to starting when the key switch is turned to the start position for a predetermined period of time.

(2) Starting state

After the tractor enters the starting state, the main

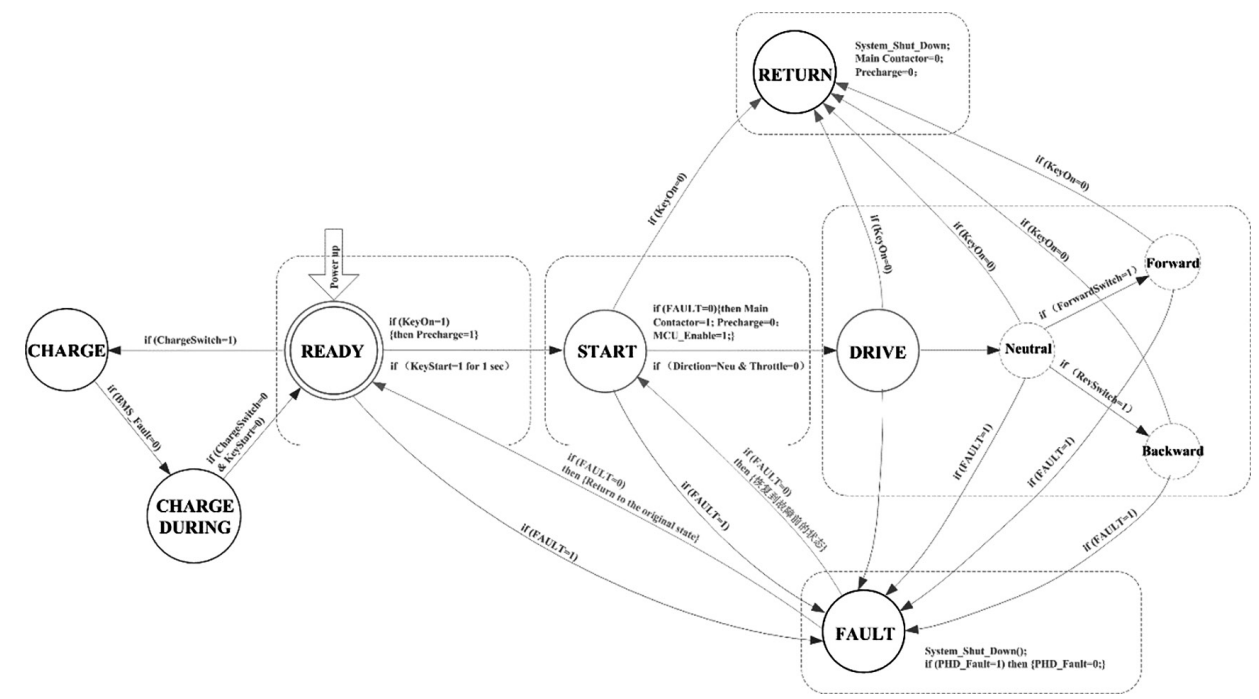

Fig. 1. Operating states and switching logic of electric tractor. 
Battery-

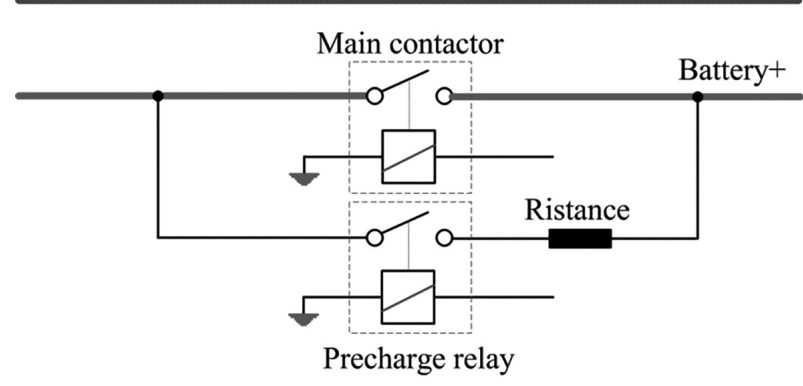

Fig. 2. Pre-charge principle circuit.

contactor is closed as long as no fault is occurring in either the driving system or the power supply system. Meanwhile, the pre-charge contactor is disconnected and PMU notifies the motor controller to enter standby mode, in which enables immediate generation of driving torque on the motor shaft once the accelerator pedal is pushed. With these preparations on track, the tractor is refreshed into the driving state, as shown in Fig. 1.

(3) Driving state

In the driving state, the PMU determines the torque demand in real time based on the input signals of acceleration, braking, expected direction, and operating status, such as tractor speed, battery output voltage, and motor temperature. The torque demand provided by the PMU is sent to the motor controller through the controller area network (CAN) bus according to the established communication protocol so as to propel the tractor as the driver wishes. The details for calculating the torque demand are presented in the next section.

\section{(4) Charge state}

As shown in Fig. 1, the ET can be switched to the charging state only from the ready state. When successfully receiving a charging request from the BMU, the PMU then sends the charging enable signal to the BMU as long as the tractor stays immobile and all driver inputs are zero. After being notified that the charging contactor has been closed by the BMU, the PMU then switches the tractor state to charge during.

(5) Charge-during state

During charging, the PMU continuously transfers the charging information to the display unit until the end of the charging process.

(6) Fault state

Once any operating parameter exceeds a predetermined threshold, the PMU immediately changes the tractor to the fault state. In this state, all current operating data are cleared to zero to avoid unexpected situations.

(7) Return state

When the key switch turns to an off position, the PMU clears all the command data and then changes the tractor state to ready.

\section{Calculation of driving torque}

The PMU plays an important role in converting the input signals from external devices, such as the accelerator pedal and gear shift lever, to torque demands that are recognized by the actuators (e.g., electric motors). The process of converting inputs to a target torque needs to be precise, smooth, and appropriate so as to achieve the optimum match between driving requirements and operating states. This process is illustrated by the flow chart shown in Fig. 3.

To ensure that the driver can control the tractor according to his intentions, the basic driving torque requirement can be calculated by

$$
T_{\text {raw }}=T_{Z}+\delta \cdot\left(T_{F}-T_{Z}\right),
$$

where $T_{\text {raw }}$ is the original target torque calculated by the PMU, $\delta$ is the throttle opening obtained from the accelerator pedal position, and $T_{Z}$ and $T_{F}$ are the calibrated torque lines that correspond respectively to zero throttle and full throttle. $T_{Z}$ and $T_{F}$ are usually determined by the values of control parameters such as creep torque, taper speed, forward regenerative braking torque, reverse regenerative braking torque, and maximum output torque of the motor. Wu et al. (2019) gives the detailed mathematical equations that determine the target torque according to these parameters.

As the ET driving comfort can be easily reduced by torque fluctuations, the maximum value of possible torque increases or decreases in each time step are limited. The resulting smoothed torque is given by

$$
T_{\text {sth }}(N)=\left\{\begin{array}{cc}
T_{\text {raw }}(N) & T_{\text {raw }}(N)-T_{\text {sth }}(N-1) \leq \Delta_{\text {lim }} \\
T_{\text {sth }}(N-1)+\Delta_{\text {lim }} & T_{\text {raw }}(N)-T_{\text {sth }}(N-1)>\Delta_{\text {lim }}
\end{array}\right.
$$

where $T_{\text {sth }}$ and $\Delta_{\text {lim }}$ are the smoothed target torque and the maximum increase/decrease amount of torque allowed in time step $N$.

For an electric motor, the maximum torque the motor can supply is usually closely related to its operating speed. In most cases, the motor can output a constant peak torque between zero and the base speed (Stöck et al., 2015; Soda and Enokizono, 2017). However, as the speed increases beyond the base speed, the maximum available torque declines predictably. Therefore, the target torque limited by the speeddependent torque capacity feature of the electric motor is given by

$$
T_{a v l}=\min \left(T_{c a p}, T_{s t h}\right),
$$

where $T_{\text {cap }}$ indicates the maximum available torque (motor torque capacity) determined by the speed point at which the motor is operating (Wu et al. 2019), and $T_{a v l}$

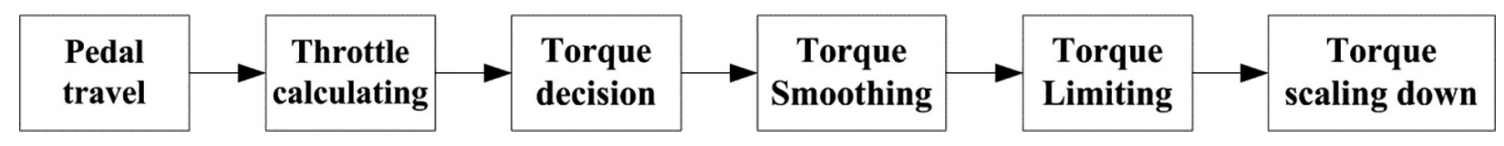

Fig. 3. Flow chart of calculating the driving torque. 
is the target torque limited by motor torque capacity.

Furthermore, an ET often experiences battery overdischarging due to its harsh working conditions. In most cases, this is caused by an excessive power request when the battery voltage level is low. To prevent the battery from overdischarging, the required torque is further limited according to the deviation of the actual voltage from the safe threshold. Thus, a deloading coefficient is introduced in Eq. (4) to scale down the torque request when the battery capacity is low.

$$
T_{c m d}=\frac{V_{B}-V_{c}}{V_{W}-V_{c}} T_{a v l},
$$

where $T_{\text {cmd }}$ is the final torque demand provided by PMU and $V_{B}, V_{c}$, and $V_{w}$ are the actual battery voltage, alarm threshold, and cutback threshold, respectively.

\section{ET powertrain simulation model}

In the HIL system, the controlled object is usually simulated by a virtual digital model. Therefore, the simulation models of the battery, motor, and entire tractor need to be sequentially established in a computer to provide the necessary logical interactive signals for the real PMU controller.

(1) Battery model

The battery model accepts a power request and returns the battery voltage, current, and state of charge (SOC). To make an appropriate trade-off between accuracy and computational complexity, the battery is modeled as an equivalent circuit comprising a perfect open circuit voltage source in series with an effective internal resistance. The open circuit voltage and internal resistance are obtained using a two-dimensional lookup table indexed by the SOC and battery module temperature (Chiang et al., 2011). Starting with the definition of electrical power and Kirchoff's voltage law for the equivalent circuit, the terminal voltage and current of the battery are obtained by Eqs. (5) and (6) as follows:

$$
\begin{aligned}
i_{B} & =\frac{2 P_{r}}{V_{o c}+\sqrt{V_{o c}^{2}-4 r_{i} P_{r}}}, \\
V_{B} & =V_{o c}-i_{B} r_{i},
\end{aligned}
$$

where $P_{r}$ is the power request, $V_{o c}$ is the open-circuit voltage of the battery, $i_{B}$ is the battery current, and $r_{i}$ is the inner resistance.

The SOC algorithm is responsible for determining the residual capacity, in amp-hours, that remains available for discharge from the battery. The SOC can be obtained by

$$
S O C=1-\frac{C_{u s e d}}{C_{N}},
$$

where $C_{\text {used }}$ and $C_{N}$ are the used and maximum capacity, respectively.

\section{(2) Electric motor model}

As the motor drive system has fast dynamics and high accuracy, the motor torque transfer function here is simply modeled as a first order inertial element with a small time delay. Thus, the actual torque output can be expressed as

$$
T_{m}=\frac{T_{c m d}}{(\tau \cdot s+1)}
$$

where $T_{m}$ is the actual output torque of the electric motor, $\tau$ is the response time for motor torque, and $s$ is a complex variable.

(3) Electric tractor dynamics model

The ET dynamics model used in this study mainly characterizes the force balance along the longitudinal direction. When we assume that the air resistance is negligible, then the available speed of the tractor is determined by a straightforward classical equation:

$$
m \frac{d v}{d t}=G T-D P-M R
$$

where $G T, D P$, and $M R$ refer to the gross tractive effort, drawbar pull, and motion resistance, respectively. $G T$ is usually expressed as a function of wheel slip $\left(s_{a}\right)$ and the dynamic weight (WD) on the driving wheels as follows:

$$
G T=W D \cdot \phi_{\max } \cdot\left(1-\mathrm{e}^{-s_{a} / s^{*}}\right),
$$

where $\phi_{\max }$ and $s^{*}$ are empirical parameters whose values are normally chosen as 0.704 and 15 (Fang and Zhang, 1987), respectively, which approximates tractor operation in a wheat stubble field.

\section{HARDWARE-IN-THE-LOOP TEST SETUP}

\section{Overview of the HIL test platform}

The HIL test platform mainly consisted of a PMU, dSPACE/DS1007 processor board, CAN bus, accelerator pedal, and switching power supply, as shown in Fig. 4a. The signal flows and logic interactions during powertrain are illustrated in Fig. 4b. During the simulation, the PMU handled the refresh of the ET operating state and the calculation of the driving torque. The torque was calculated using real time collection of signals from the accelerator and the operating states from the tractor model consisting of the combined dynamic model, battery model, and electric motor model running on the DS1007 board. The accelerator had a positive output attribute with voltages of $0.34 \mathrm{~V}$ and $3.5 \mathrm{~V}$ at zero throttle and full throttle, respectively, as the necessary PMU inputs. The CAN bus was adopted to enable data communication between the PMU and DS1007 processor. The communication protocol is shown in Table 1. The entire simulation process could be monitored in real time through a lab-designed graphical interface based on the ControlDesk program running on the upper computer.

\section{Calibration of key parameters}

As the ET performance was greatly affected by the calibration of the control parameters of the PMU, the process for determining the values of the key parameters is described in detail in this section. The three types of key parameters are torque lines corresponding to full throttle and zero throttle, the motor torque capacity, and the thresholds of battery voltage protection. 


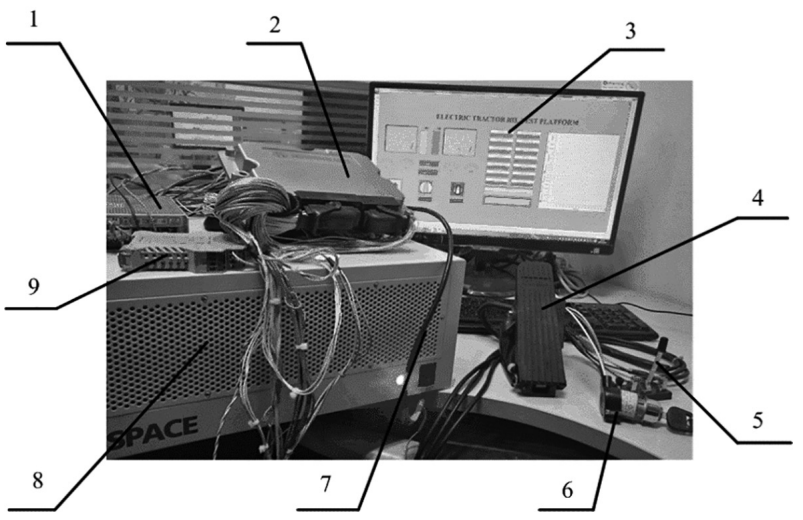

(a)

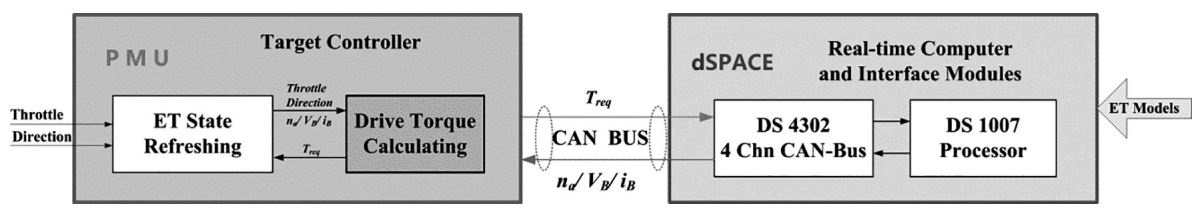

(b)

Fig. 4. Signal interaction between PMU and DS1007: (a) Configuration of PMU test platform using dSPACE; (b) Signal interaction between PMU and DS1007.

Table 1. Communication protocol between TCU and DS1007

\begin{tabular}{|c|c|c|c|c|c|c|c|c|c|}
\hline ID & Period/ms & Byte & Signal & Bit & Precision & Unit & Description & DS1007 & TCU \\
\hline \multirow{4}{*}{$0 \times 430$} & \multirow{4}{*}{20} & \multirow{3}{*}{0} & Direction & $5-6$ & 1 & - & $\begin{array}{l}0 \times 0 \text { : Standby; } \\
0 \times 1 \text { : Forward; } \\
0 \times 2 \text { : Reverse }\end{array}$ & \multirow{4}{*}{ S } & \multirow{4}{*}{$\mathrm{R}$} \\
\hline & & & Operation mode & $3-4$ & 1 & - & $\begin{array}{l}0 \times 0: \text { Standby; } \\
0 \times 1: \text { Torque mode; } \\
0 \times 2: \text { Speed mode }\end{array}$ & & \\
\hline & & & Working state & $1-2$ & 1 & - & $\begin{array}{l}0 \times 0 \text { : Standby; } \\
0 \times 1 \text { : Electric state; } \\
0 \times 2 \text { : Generation state }\end{array}$ & & \\
\hline & & $2-3$ & Current speed & $24-23$ & 0.25 & rpm & & & \\
\hline \multirow{2}{*}{$0 \times 685$} & \multirow{2}{*}{20} & $2-3$ & DC voltage & $24-23$ & 0.1 & V & & \multirow{2}{*}{ S } & \multirow{2}{*}{$\mathrm{R}$} \\
\hline & & $4-5$ & DC current & 40-39 & 0.1 & A & & & \\
\hline \multirow{5}{*}{$0 \times 210$} & \multirow{5}{*}{10} & \multirow{4}{*}{0} & $\begin{array}{l}\text { Direction com- } \\
\text { mand }\end{array}$ & $5-6$ & 1 & - & $\begin{array}{l}0 \times 0 \text { : Standby; } \\
0 \times 1: \text { Forward; } \\
0 \times 2: \text { Reverse }\end{array}$ & \multirow{5}{*}{$\mathrm{R}$} & \multirow{5}{*}{ S } \\
\hline & & & Mode command & $3-4$ & 1 & - & $\begin{array}{l}0 \times 0: \text { Standby; } \\
0 \times 1: \text { Torque mode; } \\
0 \times 2: \text { Speed mode }\end{array}$ & & \\
\hline & & & State command & $1-2$ & 1 & - & $\begin{array}{l}0 \times 0 \text { : Standby; } \\
0 \times 1 \text { : Electric state; } \\
0 \times 2 \text { : Generation state }\end{array}$ & & \\
\hline & & & Controller enable & 0 & 1 & - & $\begin{array}{l}0 \times 0 \text { : inhibit; } \\
0 \times 1: \text { enable }\end{array}$ & & \\
\hline & & $5-6$ & Torque command & $48-47$ & 0.02 & $\mathrm{~N} \cdot \mathrm{m}$ & - & & \\
\hline
\end{tabular}

As mentioned above, $T_{Z}$ and $T_{F}$ are closely related to the creep torque, taper speed, forward regenerative braking torque, and reverse regenerative braking torque. Among these parameters, the creep torque allows a small amount of torque to be applied as soon as the throttle is closed. This is used in a tractor to overcome friction during initial movement. However, too much creep torque can make the tractor uncontrollable at low speeds. Here we set the creep torque level to 5\% as a default. The taper speed determines the speed point at which the drag torque is applied. For some cases where the requirements are not critical, the taper speed can be taken as $500 \mathrm{rev} / \mathrm{min}$, and the drag torque can be taken as $25 \%$ of the maximum torque of the electric motor.

The motor torque capacity $\left(T_{\text {cap }}\right)$ that provides the maximum available torque of the electric motor at a 
given operating speed can usually be approximately fitted by the steady state torque values at $5 \sim 7$ given speed points obtained through bench experiments.

As for the battery undervoltage protection, the threshold of the power battery pack is usually determined by the composition of the battery pack. According to the ET model configuration, the battery pack comprises 105 cells with a rated cell voltage of $3.2 \mathrm{~V}$, which provides a nominal pack voltage of $336 \mathrm{~V}$. To this end, we set the safe range of the pack voltage to $85 \%-115 \%$ of the nominal value and reserved a voltage range of $10 \mathrm{~V}$ to proportionally reduce the required torque, thus obtaining the voltage protection thresholds of both alarm and cutback.

\section{Test procedure using dSPACE}

To evaluate the overall properties of the PMU, two specific testing conditions were designed as follows:

(1) ET state refresh test corresponding to driver inputs

Changing the ET state is closely related to the ET operating safety. To find out how the PMU refreshes the ET state according to the input signals from external devices, such as the accelerator pedal and gear shift lever, a start-drive-stop test was carried out on the HIL platform.

(2) Determination of driving torque during full-throttle acceleration

To evaluate how the PMU behaves during the determination of driving torque, two acceleration maneuver cases were designed.

Case A: Speeding up during normal state

This case is designed to show how the PMU behaves while it determines the required torque during the ET driving state. As the ET sped up rapidly, sudden changes may occur in the output torque of the motor. Meanwhile, the motor gradually enters its high-speed region with increasing tractor velocity. These create a need verify the effectiveness of the PMU torque determination.

Case B: Speeding up when battery charge level is low

This case is tailored to show how the PMU protects the battery from overdischarge by proportionally reducing the required torque according to the deviation of actual battery voltage from the voltage protection threshold.

\section{RESULTS AND DISCUSSION}

\section{Refresh of ET state test in response to driver inputs}

Figure 5 shows the process of the PMU switching the ET operating state according to driver inputs. When the key switch was switched from off to on at about $2.2 \mathrm{~s}$, the PMU updated the tractor from the default return state (value=7) to the ready state (value=0) according to the pre-determined state switching logic (see Fig. $5 \mathrm{a}$ and $5 \mathrm{c}$ ). In the ready state, the PMU waited for a start signal from the key switch. At about $9.4 \mathrm{~s}$, a short start signal appeared, and the state of the tractor was switched from ready to starting (value $=1$ ). Then

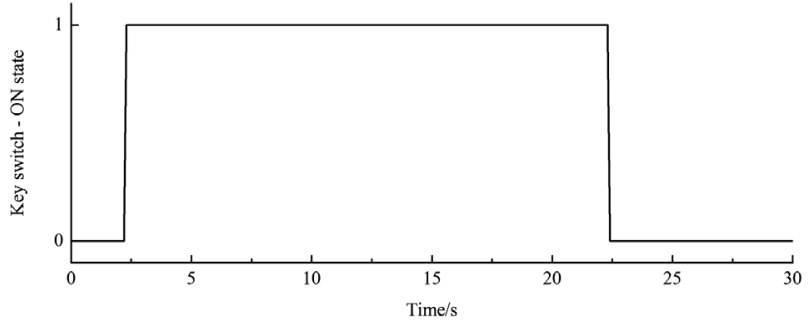

(a)

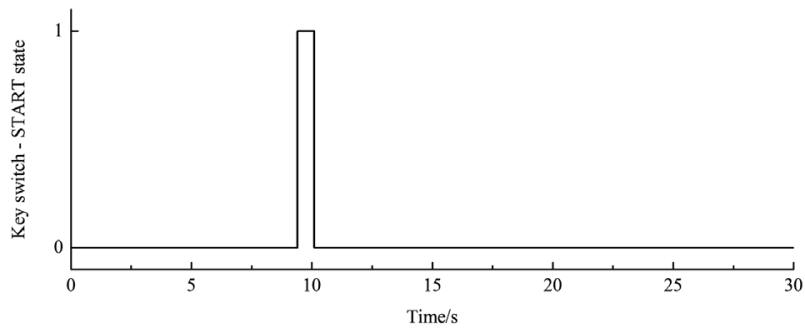

(b)

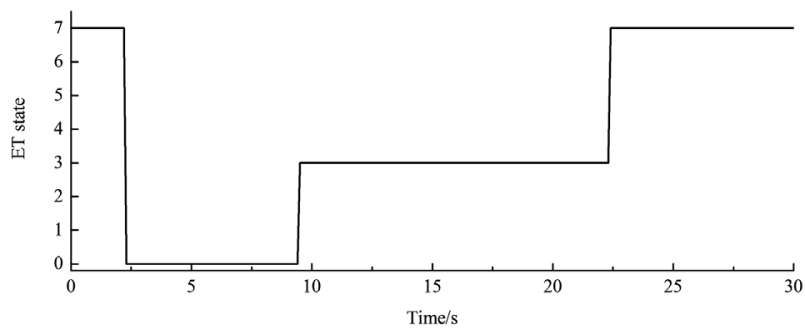

(c)

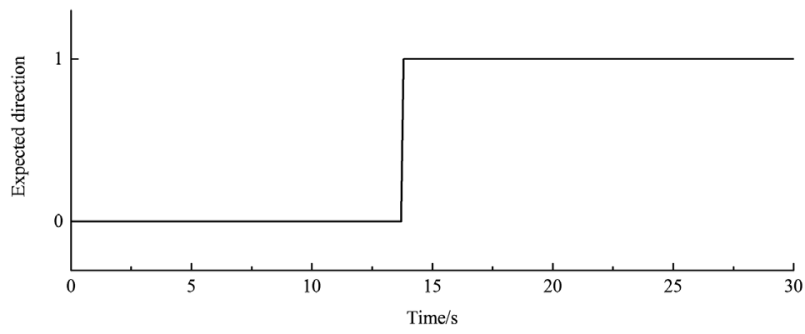

(d)

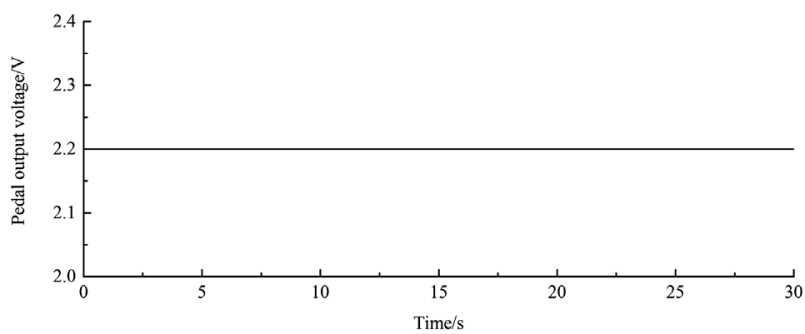

(e)

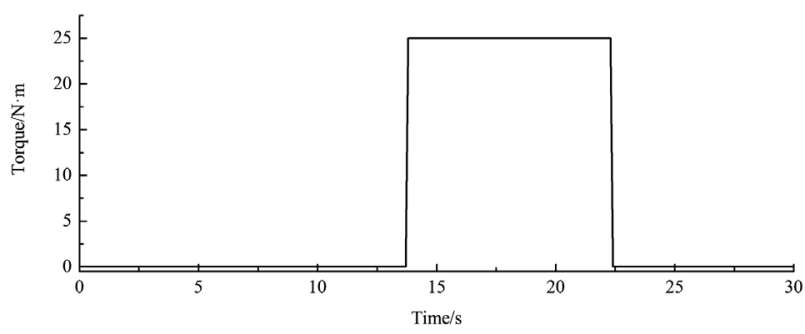

(f)

Fig. 5. State refresh according to driver inputs: (a) State value of "ON" key switch; (b) State value of "START" key switch; (c) ET state refreshed by PMU; (d) State value of expected direction switch; (e) Accelerator pedal output voltage; (f) Target torque calculated by PMU. 
the state was further quickly updated to driving (value $=3$ ), in which the driving torque was calculated by the PMU in real time in response to the pedal output voltage and the state of the direction switch, as described in section 2.1 (see Fig. $5 \mathrm{~b}$ and $5 \mathrm{c}$ ). When the key switch returned to the off state at about $23 \mathrm{~s}$, the PMU set the tractor to the return state again (value $=7$ ), which also cleared all the command values. It should be noted that when the PMU calculates the target torque in response to the pedal output voltage, only when the direction signal is valid can the pedal voltage be effectively converted to the torque value by the PMU to drive the electric motor. In other words, as long as the direction switch is in the neutral position, it is impossible to generate driving torque even though the accelerator pedal has voltage output, which is clearly shown in Fig. $5 \mathrm{~d}, 5 \mathrm{e}$, and $5 \mathrm{f}$.

\section{Determination of driving torque during full-throt- tle acceleration}

Case A: Speeding up during normal state

Figure 6a shows how the pedal voltage, which reflects the driving intention, was converted into the original target torque. As can be seen, the change trend of the target torque was basically the same as the pedal voltage. Corresponding to the quick depression of the accelerator pedal, a sudden torque increase occurred at the beginning of the simulation. Because this rapid change would cause severe physical shock to the tractor, the original torque could not be directly used as the torque demand on the motor controller. Figure $6 \mathrm{~b}$ shows that the PMU moderated the sudden torque demand increase. Clearly, a ramp-limited torque with a rising time calibrated to a certain level increased the time needed to reach the target value. This effect actually smoothed the acceleration process, although the acceleration sensitivity was weakened to some extent. Figure $6 \mathrm{c}$ shows the changes in the available maximum torque the motor can supply as the speed increases and decreases during the simulation. During the period of about $3 \mathrm{~s}$ to $16 \mathrm{~s}$, in which the motor speed was greater than 2,000 rev/min (the base speed of the motor), the maximum torque demonstrated a changing trend opposite that of the motor speed. Meanwhile, as the speed increased to more than 4,000 rev/min, the motor actually had almost no torque available. This capacity-limiting effect applied a "peak clipping" to the ramp-limited torque within the period of about $3.5 \mathrm{~s}$ to $10 \mathrm{~s}$, as shown in Fig. 6d. This effect ensured that the torque driving demand always stayed below the output capacity of the electric motor.

Case B: Speeding up when battery charge level is low

Similar to Fig. 6a and $6 \mathrm{~b}$ in Case A, Fig. 7a and 7b show how the PMU calculated the original target torque in response to the pedal output voltage, as well as the moderating effect on torque sudden changes during the acceleration simulation, and therefore a detailed description will not be repeated here. Figures $7 \mathrm{c}$ and $8 \mathrm{~d}$ clearly explain the details of the PMU reducing the driving torque in response to the battery actual voltage deviat-

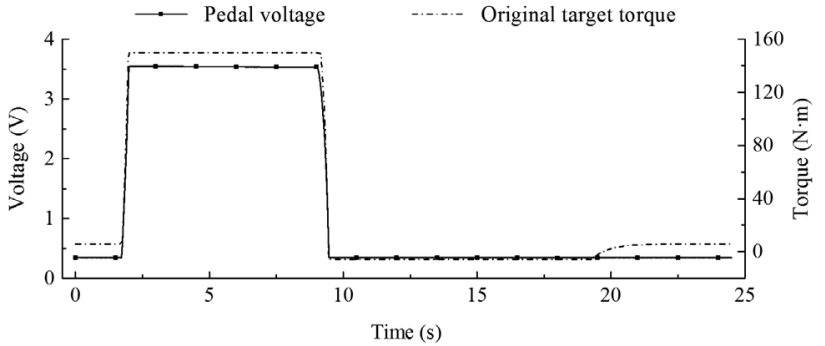

(a)

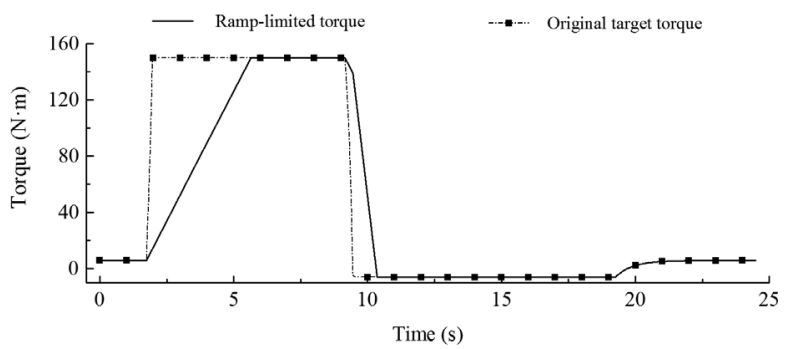

(b)

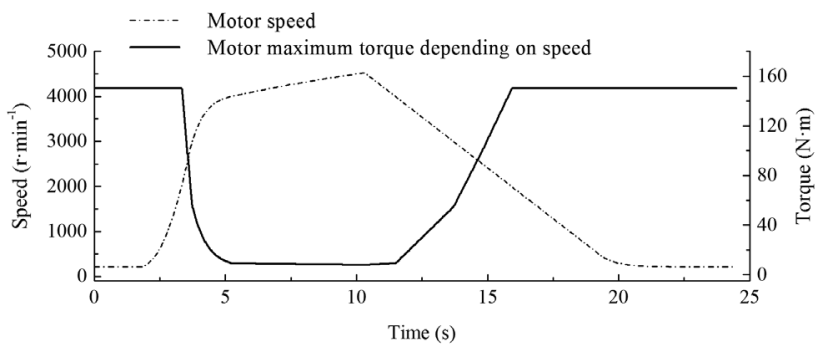

(c)

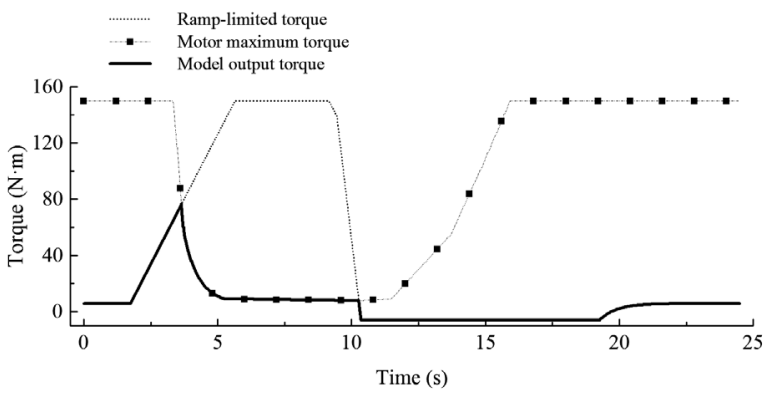

(d)

Fig. 6. Results of Case A in accelerating test: (a) Pedal manipulation and corresponding torque; (b) Time-based ramp-limiting effect on target torque; (c) Motor maximum torque depending on speed; (d) Limiting effects from both torque capacity and ramping time on torque decision.

ing from the overdischarge threshold. As the battery voltage fell down below the undervoltage warning level $(285 \mathrm{~V})$, the PMU accordingly adjusted the coefficient to less than 100\%, as shown in Fig. 7c. Meanwhile, the reduced coefficient in response proportionally scaled down the target torque, as shown in Fig. 7d, which therefore effectively kept the battery voltage above the safe level during the entire simulation. 


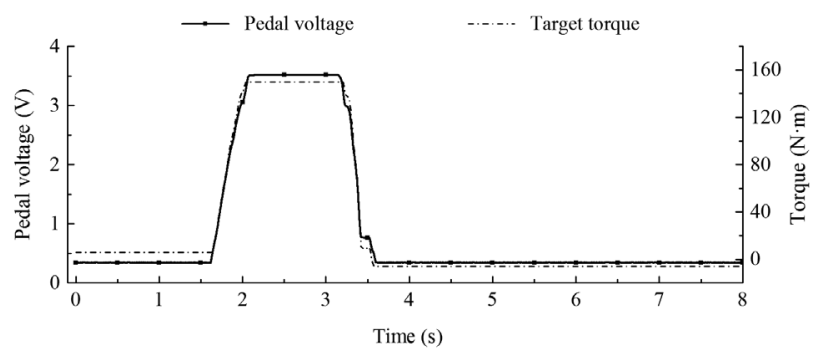

(a)

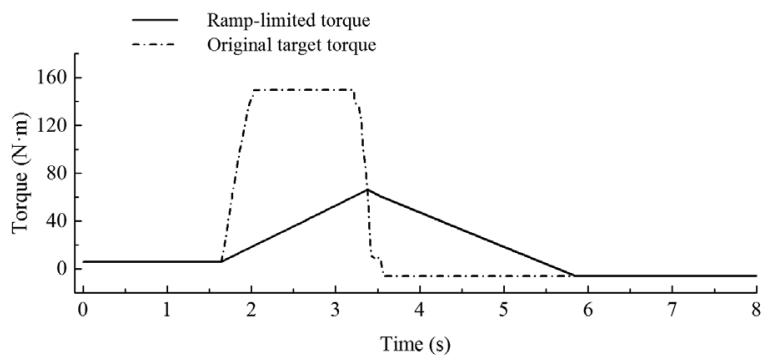

(b)

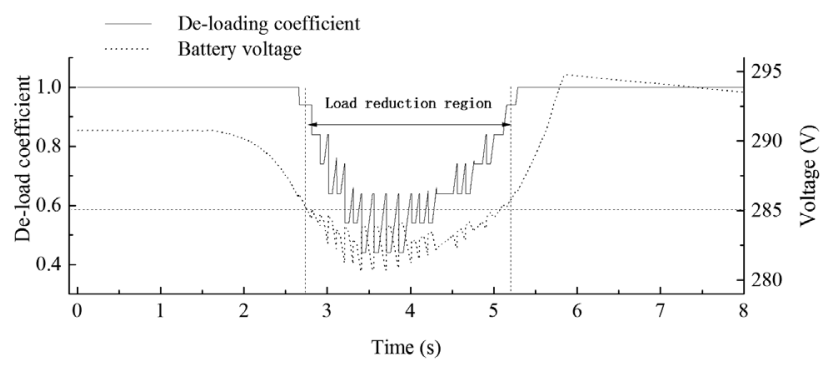

(c)

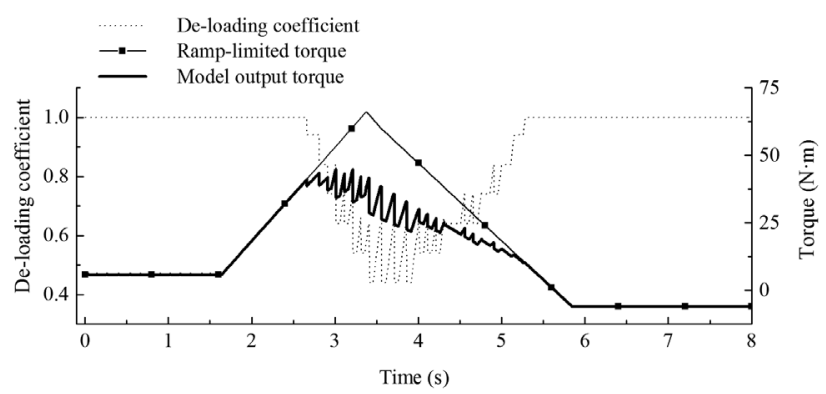

(d)

Fig. 7. Results of Case B in accelerating test: (a) Pedal manipulation and corresponding torque; (b) Time-based ramp-limiting effect on target torque; (c) Reduction of de-loading coefficient with battery voltage; (d) Combined effect of ramp limitation and undervoltage restriction.

\section{CONCLUSIONS}

The HIL simulation platform developed in this study mainly provided a way to test the performance of the PMU of an ET by virtual experiments. The HIL verification indicated that the proposed PMU was capable of managing the behavior of the powertrain by effectively refreshing the operating states of the tractor and reasonably converting the driver's intention into a torque demand. In the HIL testing, the dSPACE/DS1007 board was used to provide the necessary feedback to the PMU by real-time operation of mathematical models of the electric tractor. This makes it possible to test the controller before building an ET prototype and is very helpful for shortening the development cycle of the controller and reducing the cost of testing.

\section{AUTHOR CONTRIBUTIONS}

Zhen LI conceived the method to build the HIL test platform. Zhongbin WU and Bin XIE designed the target controller and carried out the performance test on the HIL platform. All authors assisted in editing of the manuscript and approved the final version.

\section{ACKNOWLEDGEMENTS}

The authors would like to acknowledge the financial support from the National Natural Science Foundation of China (51805535) and National Key Research and Development Plan of China (2016YFD0701001).

\section{REFERENCES}

Abdelrahman, A. S., Algarny, K. S., and Youssef, M. Z. 2018 A novel platform for powertrain modeling of electric cars with experimental validation using real-time hardware in the loop (HIL): a case study of gm second generation chevrolet volt. IEEE Transactions on Power Electronics, 33(11): 9762-9771

Alcock, R. 1986 Tractor - implement system. Avi Publishing Co. Inc., Westport, pp. 141-152

Arjharn, W., Koike, M., Takigawa, T., Yoda, A., Hasegawa, H., and Bahalayodhin, B. 2001 Preliminary study on the applicability of an electric tractor (part1). Journal of JSAM, 63(5): 92-99

Chiang, Y. H., Sean, W. Y., and Ke, J. C. 2011 Online estimation of internal resistance and open-circuit voltage of lithium-ion batteries in electric vehicles. Journal of Power Sources, 196(8): 3921-3932

Fang, Z. H., and Zhang, W. C. 1987 The prediction of tractorimplement unit traction performance. Transactions of the Chinese Society for Agricultural Machinery, 18(1): 13-20

Fatemi, A., Ionel, D. M., Popescu, M., Chong, Y. C., and Demerdash, N. A. O. 2018 Design optimization of a high torque density spoke-type PM motor for a formula e race drive cycle. IEEE Transactions on Industry Applications, 54(5): 43-54

Gonzalez-de-Soto, M., Emmi, L., Benavides, C., Garcia, I., and Gonzalez-de-Santos, P. 2016 Reducing air pollution with hybridpowered robotic tractors for precision agriculture. Biosystems Engineering, 143: 79-94

Hammond, G. P., and Hazeldine, T. 2015 Indicative energy technology assessment of advanced rechargeable batteries. Applied Energy, 138: 559-571

Liu, Z., Chai, J., Zhang, J., and Cui, G. 2015 Recent progress in cellulose-based composite separators for high performance lithium ion batteries. Acta Polymerica Sinica, 11: 1246-1257

Min, Y. F. 2011 Vehicle electric module virtual calibration. Control Engineering of China, 18(A1): 125-127

Moreda, G. P., Muñoz-García, M. A., and Barreiro, P. 2016 High voltage electrification of tractor and agricultural machinery - A review. Energy Conversion and Management, 115: 117-131

Mousazadeh, H., Keyhani, A., Javadi, A., Mobli, H., Abrinia, K., and Sharifi, A. 2010 Evaluation of alternative battery technologies for a solar assist plug-in hybrid electric tractor. Transportation Research Part D: Transport and Environment, 15(8): 
$507-512$

Nelson, R. 2013 Hardware-in-the-loop test drives development. EE: Evaluation Engineering, 52(10): 24-27

Obert, M. 1972 Electric farm vehicles - are they feasible. Agricultural Engineering, $\mathbf{5 3}(8)$

Schreiber, V., Ivanov, V., Augsburg, K., Noack, M., Shyrokau, B., Sandu, C., and Els, P. S. 2018 Shared and distributed x-inthe-loop tests for automotive systems: feasibility study. IEEE Access, 6: 4017-4026

Soda, N., and Enokizono, M. 2017 Stator shape design method for improving power density in PM motor. IEEE Transactions on Magnetics, 53(11): 1-4

Stöck, M., Lohmeyer, Q., and Meboldt, M. 2015 Increasing the power density of e-motors by innovative winding design. Procedia CIRP, 36: 236-241

Wu, Z. B., Xie, B., Chi, R. J., Ren, Z. Y., Du, Y. F., and Li, Z. 2019 Driving torque management model for electric tractor in field cruise condition. Transactions of the Chinese Society of Agricultural Engineering (Transactions of the CSAE), 35(4): 88-98 
